January 2017

\title{
The Arts of Amnesia: The Case for Audio Drama, Part Two
}

Neil Verma

North-Western University, Chicago

Follow this and additional works at: http://ro.uow.edu.au/rdr

Part of the Audio Arts and Acoustics Commons, Digital Humanities Commons, Radio Commons, and the Theatre and Performance Studies Commons

Recommended Citation

Verma, Neil, The Arts of Amnesia: The Case for Audio Drama, Part Two, RadioDoc Review, 3(1), 2017. doi: $10.14453 /$ rdr.v3i1.6

Research Online is the open access institutional repository for the University of Wollongong. For further information contact the UOW Library: research-pubs@uow.edu.au 


\title{
The Arts of Amnesia: The Case for Audio Drama, Part Two
}

\begin{abstract}
This article examines what the relationship between audio drama and radio drama might illuminate about both forms. Drawing on some 40 podcasts and other audio forms that take a serial structure, I explore the rise of audio drama podcasts since 2015 and situate them in both a more recent historical context since the late 1990s and in a broader history stretching back to the first Golden Age of radio. By listening closely to key works on Serendipity, Homecoming and other podcasts, I argue that contemporary audio has profound potential to change both how we listen and how we relate to the sound media of the past.
\end{abstract}

\section{Keywords}

Radio Drama, Audio Drama, Homecoming, Serendipity, Radio History, Podcasting 


\section{The Arts of Amnesia: The Case for Audio Drama, Part Two}

By Neil Verma, Northwestern University

\section{Listening Backward}

Over the century or so of its history, radio drama has earned much love but little respect. It has given no one wealth, perhaps a half dozen people fame. Few devote a lifetime to mastering it. Some of its greatest proponents actually contribute little to it: poet Archibald MacLeish was revered for his work, but couldn't stand devoting half a year to writing a script that's gone in a half-hour on air; since the 1970s Tom Stoppard has averaged about one radio play a decade (Donaldson 1992: 270). Louis MacNeice is probably the only writer to have the distinction of dying for radio drama, sort of - his recording trips to record sound from caves for his 1963 drama "Persons from Porlock" probably contributed to the bronchitis that killed him (Bloom 2016). There are hundreds of fan sites for radio drama on social media and archives of old radio scattered around the United States (the recent Radio Preservation Task Force initiative by the Library of Congress stands to expand access to this tremendously), as well as exhibits, festivals that come and go, and awards (The Giles Cooper Award, Third Coast Awards, The Peabody Awards, The Prix Italia, Prix Marulic, now the Sarahs) but there seems no permanent institution in the public sphere intended to ennoble it in the United States, no equivalent of the Criterion Collection or Library of America book series, for instance. It can even appear that the field has no critical tradition, although in reality it is only submerged (as the bibliography of this essay shows, there is a rich scholarly tradition that is unknown outside the academy) or neglected, such as the brilliant work done by critical venues from Variety in the 1940s to The Timbre and RadioDoc Review recently. Ironically, to lament radio's lack of a critical 
tradition is one way to join that critical tradition - there is an uncanny resemblance in tone and argument, for instance, between producer Sarah Montague's recent "Toward a Poetics of Audio" essay for Serendipity and Variety radio critic Bob Landry's "The Improbability of Radio Criticism" essay for Hollywood Quarterly back in 1946 (Montague 2017; Landry 1946).

Perhaps uniquely among modern expressive arts, radio drama is caught in a paradox. It is irrecoverable, the vestige of a culture that has evaporated into thin air, yet it is also in a constant state of being-invented, just getting going, with its great masterpieces still ahead of us. Indeed, a promising future has long been radio drama's rhetorical position when it comes to boosting public interest. "We don't know what radio can do yet" said Columbia Workshop founder Irving Reis to the Washington Post in 1936, a dozen years after radio dramas had begun airing; "We're trying to explore what the form can be," said producer Eli Horowitz to the New York Times in 2016, explaining to Vanity Fair that drama podcasting is at "the tippiest tip of the iceberg" (Brunel 1936; Hess 2016; Robinson 2016). Of course, on one level, Reis and Horowitz are merely showing some public relations hustle. But there is something else behind it, too. For both dramatists, some eighty years apart, a perceived shift in the material conditions of production (network radio for Reis; ease of digital production and distribution for Horowitz) had the concomitant benefit of making the idea of creating dramatic worlds out of sound seems like something new and compelling, remuneration be damned.

Another problem is that radio drama is difficult to define. In my work I tend to follow the minimalist idea that radio drama should be on-air and ought to feature a "scene" in which a "character" performs an "action," but setting out bare parameters like those doesn't reign in usage one bit (Verma 2012: 4-5). Follow uses of "radio play" in American English over the last 
nine decades and you will find that it is neither always "radio" (it refers to vinyl, tapes, digital forms and stages; "liveness" in production is an exception, not the rule) nor always "drama" or a "play" (it can lack story, action, characters, settings). The relation to theatre is unclear. As Milton Kaplan observed in an early book on verse radio, many radio plays wouldn't work on stage because they tend to have very little conflict or personal tribulations (Kaplan 1949: 110). It's hard to imagine a category that contains both the workhorse serial The Archers, some 18,000 episodes long, and Antonin Artaud's 1947 scatological indictment of modernity, "To Have Done with The Judgment of God." Despite this difficulty with definition, or perhaps because if it, radio drama has given us great works that range from the enigmatic to the soulful (Think of Samuel Beckett's "All That Fall" and Yuri Rasovsky's "The Dybbuk") as well as resonant pieces about modernity (Pare Lorentz's "Ecce Homo," Giles Cooper's "Under the Loofah Tree" and Stoppard's "Albert's Bridge") and some of the most interesting sound atmospheres in all the arts (From Orson Welles' "Hell on Ice" to Jonathan Mitchell's "Sylvia's Blood"). But ask anyone about it and you will find that it still conjures little more than soft-focus images of unimaginative hacks with coconut halves poised to make the sound of horse hooves.

As a result, radio drama has no canon of masterpieces or set of auteurs whose merits are hotly debated by swells at cocktail parties. Anyone can name dozens of novelists, painters or filmmakers, but just try the same trick for radio directors. Even just try saying "radio oeuvre" aloud. This cultural amnesia about radio means that, alone among contemporary arts, radio drama also has no habit of homage, what Michele Hilmes calls "a sense of expressive continuity" that links one work to the next (Hilmes 2014). Creators tend not to obsessively explore antecedents with the vigour that filmmakers study films, novelists novels or poets 
poems, rarely producing works of radio art about other works of radio art - one recent example is Colin Black's beautiful and fascinating 2014 sound composition In Search of Captain Cat of Llareggub, which locates itself in the imagination and experience of a key character from Dylan Thomas's 1954 radio play Under Milk Wood.

But works like that are few and far between, as radio's deepest roots are not felt in its many current branches. Michele Hilmes likens the situation to a cinema that can't recall what movies were like before Star Wars. This is the truth behind the laments of writers such as Montague and Landry. Everyone enjoys "The War of the Worlds" but how many out there know that a recording of Langston Hughes's long lost "The Man Who Went to War," a 1944 treasure as valuable as any Orson Welles reel, was recently rediscovered by Hilmes and digitised at the Library of Congress? Today's producers in the US run from their own legacy at full tilt, wishing their work to be heard as something, anything, other than "old time radio." Even the term "radio drama" is a drag, hence the neologisms I've been using in this essay, like "audio drama," "radio fiction," "full cast audiobook," "audio sitcom" or "scripted series." By "othering" radio drama, it's easy to fall into a determinism that misses cross-fertilisation and common experiment. There is no better example of production for novice podcasters than Neil Gaiman adaptations on the BBC in recent years such as Neverwhere and Good Omens, both of which were made as event radio, but which are also marketed as full cast audio dramas for download. And in the last 12 months we've had a minor boom in binaural audio experimentation that crosses both radio and streaming, with examples on The Truth ("Visible"), Campfire Radio Theater ("Abduction at Willow Woods") online and also Marc Beeby's new adaptation of "War of the Worlds" on BBC Radio 4 and short work on Radio 3's Between the Ears ("Track 12," an 
adaptation of a story by J. G. Ballard). Still, the most prominent voices out there describe radio drama in ways that seek to distance it from audio drama, using terms like "old-school" and "stodgy," and emphasising the importance of doing away with the trappings of what Radiotopia Executive Producer Julie Shapiro calls radio drama "with a capital R and D" in favour of something more "contemporary" (Hess 2016).

It's important to realise that such rhetorical gestures are part of a tradition as venerable and generative as any in the history of radio drama. As Eleanor Patterson has shown, as early as 1963 (just a heartbeat after "old time radio" closed up shop) radio producers seeking to revive radio drama were using phrases just like Shapiro and others might have chosen - "we don't want to resume radio drama at the point where it left off" and "[A new program] will not represent a return to old-time radio drama" (Patterson 2016). Over the past half-century, the only thing more reliable than the constant revival of radio drama is the insistence that what ensues is not really a revival, but something utterly new, instead. That position puts creators and scholars at cross-purposes. In recent years, many in the scholarly community have been exploring the qualities of classical radio drama, recapturing the art of production, writing, direction and acting, and explaining how these qualities spoke to a variety of social groups (e.g. Battles 2010; Cohen et al 2009; Crisell 2006; Gilfillan 2009; Guralnick 1995; Hilmes and Loviglio 2002; Kahn and Whitehead 1992; Razlogova 2011; Russo 2010; Verma 2012). In academic circles, we are often working against outright dismissals of this material, and hopeful that practitioners today would bolster our case. It's true that old radio is The Shadow and Ozzie and Harriet, but there's a lot more to those shows than meets the ear, and radio is also Carl Sandburg, Edna St. Vincent Millay, Antonin Artaud, Louis MacNeice, D.G. Bridson, Arthur Kopit, 
Norman Corwin, Arch Oboler, William N. Robson, Harold Pinter, Firesign Theater, Yuri Rasovsky and many others. Even works like Dragnet, Suspense, Dimension $X$ and Calling all Cars that come across as overly mannered to the modern ear have a depth revealed by dedicated and careful listening.

But scholars can't make that case alone. An audio drama that listens backward with interest and passion is essential. Just as what we now think of as the masterpieces of film noir were deemed mere cheap "gangster pictures" until their aesthetics were rethought by French and American filmmakers a generation later, the new audio drama has a chance to redeem everything dismissed, parodied and derided about traditional radio (Montague 2017; Naremore 1998). A play like Kaitlin Prest's "Strangers in a Small Café," which tracks the thoughts, notes and conversations of a series of Brooklyn writers and artists, might be enriched by listening to it alongside Under Milk Wood, which gives similar access to the interiority of the denizens of a small Welsh village. The "Thistle Man," a haunting creature stalking the narrator of Alice Isn't Dead across the country, becomes more interesting when he is compared to his distant relative, the titular character in Lucille Fletcher's 1942 radio play "The Hitch-Hiker," who likewise chases the narrator across a ghostly nation, appearing over and over again by the side of the road. Indeed, to those who believe audio drama is only contemporary in flavor, I suggest taking a long hard listen to the disembodied voices from beyond the grave, brain experiments, fantasies of inanimate life, undead creatures, dystopias, time paradoxes, mass disappearances, alien invasions, love stories and conspiracies that form the stuff of contemporary audio storytelling and realize just how far we haven't gotten from themes, techniques and tropes that preoccupied radio narrative in the past. As Andrew Bottomley has trenchantly pointed out, 
audio fiction is an act of remediation, and one of the things it remediates is classic radio (Bottomley 2015). The challenge is to see this coincidence as an opportunity rather than a problem, to transform the relationship between "old" radio drama and "new" audio drama from one of mutual antipathy to one of mutual vindication.

\section{Coming Home}

I’m emphasising work that speaks back to historical programs in order to prompt a paradigm that resituates podcasts with their antecedents in order to make listening yield a more challenging set of questions. Rather than asking how Serendipity's "Almost Flamboyant" echoes proximal practices of reality radio, for instance, we should ask how that whole genre is related to classic urban exploration dramas from the exuberant "Broadway Evening" by Leopold Proser to the murderous "August Heat" by William Spier. Instead of hearing the way the work of Dirk Maggs has influenced the sound of such programs as We're Alive, Locke \& Key and other adventure programs, ask what makes Maggs's style so durable, how it relates to the techniques of Carleton E. Morse of I Love a Mystery and Tom Lopez of The Fourth Tower of Inverness, two writers who likewise solve complex serial narrative action problems in closed spatial environments, but do so in vastly different ways. When $\mathrm{X}$, the unnamed character-narrator of Issa Rae's Fruit, spends whole episodes playing games of cat-and-mouse to avoid verbally revealing the secret of his sexuality, while relentlessly telling us about it, the dramatists are employing a structure common in "under cover man" thrillers from I Was a Communist for the FBI to Counterspy in the 1950s to Tom Stoppard's "The Dog It Was That Died" in the 1980s and Robert Forrest's adaptation of John Le Carre's "The Spy Who Came in From the Cold" in 2009. 
In other words, from a narratological and aesthetic point of view, $\mathrm{X}$ isn't that different from The Man Called X. And the comparison opens interpretive possibilities. Heard in the context of Fruit, it becomes clear how white heteronormativity is the subtext of I Was a Communist; heard alongside I Was a Communist, politics becomes a clearer theme in Fruit.

It's this trans-historical echoic effect that today's dramas have the chance to actuate, and in doing so make audio drama listening precise and pensive, deeper as an activity. Take this month's most exciting serial, Bronzeville. In offering copious vantage points on a highly specific place and time, Bronzeville employs what I've called the "kaleidosonic" style, which shifts between a number of shallow scenes across a social geography relatively rapidly, drawing in the voices of fortune tellers and preachers, hustlers and cops, bankers and gangsters, new arrivals from the Great Migration and others. Through segues and an emphasis on the present tense, characters rhetorically form a bonded group. No matter what the specific events we are listening to - in this case the trails of the Copeland Brothers racket - the rhetoric of a kaleidosonic program is one in which voices accumulate into a coalition, emphasising equality and pluralism. Radio writer Norman Corwin perfected this style in poetic dramas of the midcentury in which time and place interlock through a set of storytelling forms, but it's impossible to get listeners today to get a historically thick sense of what it meant to listen to plays like "We Hold These Truths," "Unity Fair" and "The Midwest: Breadbasket and Arsenal," whose titles alone make people roll their eyes (Smith and Verma 2016). Bronzeville is exciting for a lot of reasons that have to do with representation, an African American show by African Americans about African American history, and an unexpected one is that it might teach us how to listen 
appreciatively (and critically) to Corwin again, and to thereby "re-memory" the listening public in the ways in which audio world-making both includes and excludes voices.

The kind of recontextualised listening I propose is also a way to train the ears on aspects of audio craft, rather than stopping at the level of character and story in assessing a particular piece. Let's return to the three blockbuster podcasts of 2015 that I mentioned at the start of this essay: The Black Tapes, The Message and Limetown. Criticism about these programs emphasises how they borrowed from Serial the trope of the female podcaster protagonist; at this rather obvious point the analysis stops. But this is the least unexpected aspect of these programs. Consider, for instance, how all three use sounds that walk the boundary between illustration and affectation. Take Limetown. Most episodes of the program follow a pattern. Reporter Lia Haddock makes contact with a survivor of the disappearance. Eventually the two meet and the survivor gives a long monologue about what she remembers. Although at no point are there indications that the play segues back in time to the scene of the Limetown disappearance - "we" are never sonically "in" Limetown, only listening to those who were there as they speak to us from a series of locales in the present (secret waterfalls, trailers, hidden lairs, closed up shops, foreign parks). But something odd happens in the audio. During each monologue, a sonic element of the story-within-the-story is reproduced in the underscore with just enough stylisation to make it seem there but also nonpresent: a Limetown cleaner remembers the sound of pages being torn from twin drawing easels during a mind-melding experiment, and we hear it; a man who raises pigs for experiments remembers the sound of an alarm bell that we catch in the soundscape; a survivor recalls the sound of a mob leader with a megaphone as a funeral pyre is lit. It's a sonic code for memory, the auditory equivalent of a 
thought bubble, and it gives the scene a thin new tier for its depiction, a kind of sonic mezzanine.

This feature recalls the titular "Message" in The Message, an abstract sound composition that becomes a dramatic object in the play, with the podcaster following events, struggling over whether or not to present it to our ears as well. The composition is the centrepiece of the series, standing within but also apart. There is a similar recording in The Black Tapes, one of whose storylines involves a cursed composition (the "Un-sound") that supposedly brings death once heard. Where the stylised sound events in Limetown break the naturalistic sonic language of the program, creating an abstract sense of the past, "The Message" and "The Un-sound" break the frame of the narrative by proposing that they could be harmful to the listener herself, too. Elsewhere I've made the argument that classical radio drama wasn't just a theatre of the mind, but a theatre about the mind, largely in its embrace of sounds that urge and compel, seeming to not merely illustrate some physical event, but to alter or distort the field of the "reality" of the fiction in which they resound (Verma 2012: 114-59). In all three of these current programs, sounds work like viruses between consciousnesses, and between the inside and the outside of the fiction, giving these plays a psychology, an unconscious. Each sound has a quality of want in its relation to us. It is a remarkable mutation of the dramatic preoccupations of the past, and indeed a late metaphor for the fantasy of radio itself, a medium that has done more to change the fabric of reality through sound than any other, to cast spells, to alter minds, to connect bodies.

If my proposal is for the aesthetics of serial radio drama to leave TV and film behind and "come home" to radio, then the series to bring that argument home is, naturally, Homecoming, 
one of the few high-profile programs to show overt affection for old radio, even noting the influence of Lucille Fletcher's Suspense play "Sorry, Wrong Number" at the outset. The series foregrounds memory loss, strongly echoing several other Suspense plays on this same subject ("The Black Curtain" with Cary Grant, "Mission Accomplished" with James Stewart, "The Search for Henri Lefebvre" with Orson Welles), helping to dispel the amnesia of radio art precisely by depicting the arts of amnesia. The podcast also exhibits the central role of what I call audioposition, where we "are" according to what we "hear" (Verma 2012). In radio, both terms are manufactured. There is no "natural" where-to-listen-from in the world of the fiction, and we can't ask what events "should" sound like according to the position of the camera, proscenium or other element forming a window onto the scene. No microphone is ever alone, of course, as more than one is almost always being used and much that's recorded is being remixed, but each opens a singular world uncontradicted by some other readily extracted element. A space may not sound acoustically similar to what the dialogue suggests, but both that sound and dialogue pass through the same sensory aperture. This is why the rhetoric of position matters deeply in radio and audio drama formats, since it isn't defined by anything else and touches every aspect of the craft of audio, from writing to soundscape, from Foley to vocals. It is also a diffuse aesthetic issue, ungoverned by any one specific instrument, and yet it brings more focus to the drama than anything else. In interpreting traditional radio, audioposition is an essential concept because it helps to frame moral alignments, to feel suspense, to teleport from place to place, to experience diegetic time. Audioposition is far from the only thing that matters, but without a sense of where, there can be no sense of when, what or why, let alone a sense of uh-oh, whew or yuck. 
With that in mind, let's explore the three principal audiopositions that we hear most often in Homecoming. In the first, we hear interview tapes recorded at a military base near Tampa, in which case worker Heidi Bergman (Catherine Keener) gets to know her client, a soldier with PTSD returned from overseas named Walter Cruz (Oscar Isaac), who is there to learn to deal with his "bad thoughts" after the loss of a member of his unit who died horribly in a senseless incident at a traffic control point overseas. The dialogue between Heidi and Walter is warm and flirtatious, intended to chronicle the creation of rapport. In an early episode, Walter tells Heidi of a prank in which he conned a soldier in his unit into believing in a made-up sequel to the film Titanic, before mentioning a comrade's death in an understated way. As the counselling sessions continue, Heidi helps Cruz work through his memory, express incredulity toward the meaning of his work at the checkpoint, and plan for a future in a new career. The office space in which all this occurs is three-dimensional, carved out with prominent sonic elements, including a backdrop of the bubbling of a fish tank, as well as the exterior call of a bird (a "protected species" we are told) and the interface of the tape recorder itself, which is often audibly handled in a way that produces a palpable wall between the space of recorded event and that of its reception. The room is coded both as domestic in Heidi and Walter's interplay, but it is also increasingly carceral: surveillance mikes are everywhere in the Tampa facility, there is a false "escape" sequence in which Cruz and his roommate run away only to discover themselves in a retirement community, and Heidi and Walter daydream a road trip, the sort imagined by prisoners. The facility is a kind of traffic control point for memory, a river Lethe. 
In the second repeated setting, we hear a series of internet-based phone calls between Heidi and her boss, Colin Belfast (David Schwimmer), who is travelling the globe as he raises funds for their project, the "Homecoming Initiative." We gradually learn that Heidi's emotional labour is only a ruse; the true goal of the project isn't to rehabilitate soldiers coming home to society but to entirely erase trauma memory through a combination of drugs (administered through food in the mess hall) that will enable them to return to the battlefield more quickly. In contrast with the first setting, this one is overtly hostile. Colin takes Heidi to task for minor rebellions among Walter's peers, accusing her of "shitting on their results" and "erratic emotional outbursts." Our audioposition is in the 2-D claustrophobia of telephonic space, where Heidi can't get a word in edgewise thanks to a sonic flatness emphasised by Colin's allusions to deeper spaces (the Detroit airport, the roads of Dubai) that we can't quite hear, by his constant technical problems, and by his penchant for using these conversations to play surveillance tapes from the Tampa facility that add to a growing paranoia. This is an allusion to "Sorry, Wrong Number," with Heidi's voice thwarted in a flat vocal space in the same way as invalid Mrs. Stevenson is ritually dismissed by authorities in her pleas for help in Fletcher's play. Note that in both of Homecoming's first two settings our audioposition is within a technological device - we are "inside" a recorder in the office, then "inside" Heidi's laptop making a call - but in the former we lose a sense of that mediation and come to feel intimate companionship with nearby interlocutors. The strongest sense of intimacy is achieved not through the absence of mediator altogether but by its dissolution over the course of a scene. Meanwhile in the scenes in which a similarly prominent mediator refuses to vanish, there is an accompanying sense of a highly gendered asymmetry of power. A concluding episode has a nice reversal of this effect, 
when Colin grovels for help to his own superior Audrey Temple (Amy Sedaris) and receives only a comeuppance.

The third setting is different from the other two. It is characterised by a time period rather than by a place. Moreover, there is no flimsy narrative pretext to account for the existence of the recording we are listening to by attaching it to a diegetic recording device. Instead we are in the scene, as if following intimately over the shoulder of Heidi and segueing across the space of the fiction alongside her. It is five years later, and Heidi is working at a diner near her elderly mother whom she regularly visits at a nursing home. Thomas (Aaron Serotsky), an agent of the Department of Defense, arrives at the diner and begins probing her memories of the Initiative, which are vague and deeply buried. Over several episodes, we begin to understand that her own memories had been altered by drug therapy, as Colin (newly anonymous to her) comes back into her life (another homecoming) and she returns to the scene of the Initiative experiments. At first Heidi has trouble remembering, but the call of the bird outside her office brings parts of it back. This sequence sounds most like a classical radio drama. It also teaches you how to listen to dramas of that period, by emphasising depths (Heidi moving around the restaurant; through the nursing home; in a parking lot and restaurant; a long silence in Thomas's car), as well as spaces of dynamic motion, such as a Ferris wheel scene and Heidi's escape from Colin across passing traffic. In the present we are attached to a body, not just adjacent to a voice in conversation, and the world that surrounds that body contains fragmented, refracted evidence of the story. The amusement park ride is a (somewhat forced, I concede) metaphor for Heidi's predicament, caught by circular forces. At the nursing home, we repeatedly hear a TV with a news story about therapies to improve "brain fitness" deep in the 
background (you need good headphones to hear it), a hint at the speculative drug that is the premise of the action. In this way, story information is hidden away in the depths of the audio and the shapes of movement, forcing the listener to a level of auditory projection that nondramatic radio never requires.

To sum up, Homecoming's three main settings are, respectively, three-dimensional (the office), two-dimensional (the phone) and four-dimensional (the present), a set of audioposition schemes that are constantly "talking" to us through and behind the events that take place across them. The first two are like an audio drama and the third like a radio drama. That's why the series feels like it squeezes you and releases you over and over again. Like many classic radio plays - Archibald MacLeish's "The Fall of the City," Richard Hughes's "The Comedy of Danger," William Robson's "Three Skeleton Key" - the what of the drama only exists in the where. In Homecoming, two-dimensional conversations are claustrophobic, choked (Heidi can hardly get a full sentence out) and four-dimensional life is precarious (she often speaks of alienation, "It's like it wasn't even me"), but the therapy room avoids both. That is, until Walter's mental conditioning has taken hold and he forgets the anecdote about Titanic (a sign of disaster) and the room becomes uncanny. The only comfortable space to occupy in the entire fiction has only had a false sense of safety all along; the atmosphere of a home has masked the reality of a prison, not vice versa. Walter can no longer remember the details of his trauma, or much else. Most importantly, he no longer feels frustrated by the meaninglessness of his task overseas, and becomes eager to re-enlist.

Through its various devices, then - vanishing mediator, use of sonic depth to hide story information, and the variation in the rhetoric of dimension - the sound design manages 
exposition and mood, coaxing these two ordinarily separate dramatic elements into conspiracy. This is what makes this play so classical in spirit if not in content. Homecoming is using sound as rhetoric and so it must necessarily teach you how to listen to it. What matters about audio drama, after all, is that even when the stories are implausible and the acting mediocre, it is capable of altering the manner in which we listen, producing an "ear" for itself, and to thereby make the world around us sound a little strange. That is a noble errand.

In the end of the season of Homecoming, Heidi realises that the drug program wasn't eliminating memories in a targeted manner, but was also brainwashing Walter and the others of unrelated memories. The "smart bomb" approach had been a lie all along. Heidi decides to give Walter an extra portion of the experimental drug to make his return to the battlefield impossible, and to take it herself, as a penance for her sins and to deny Colin success. We now know why the narrative gap between settings occurred. Heidi's homecoming to the Tampa office building five years later is the beginning of rememory about all these events. The moment she hears the signal of the bird's call, something that we had first noticed in the very first episode, she begins to remember, and Thomas supplies her with the very tapes we have been listening to all along to jog her memory, thereby aligning her ear with ours in space and time; in this closing of the narrative loop, we know that Heidi could be a hidden simultaneous auditor, just like us. This alignment through narrative structure makes me think that although Homecoming may not be the "breakthrough" audio drama that many in the podcasting world are expecting (do we need one?), it feels special right now because its careful work produces a canny aesthetic lesson. It is precisely by listening to her own "audio drama" that Heidi's "radio 
drama" begins to make sense, and as we listen for her to remember, we are remembering how to listen.

\section{Bibliography}

Abel, J. (2015) Out There on The Wire: The Storytelling Secrets of the New Masters of Radio. New York, Broadway Books.

Arnheim, R. (1986) Radio. Salem, NH, Ayer.

Barnouw E. (1947) The Radio Writing Handbook. Boston, Little, Brown.

Battles, K. (2010) Calling all Cars: Radio Dragnets and the Technology of Policing. Minneapolis, $\mathrm{U}$ of Minnesota Press.

Berry R. (2016) Podcasting: Considering the Evolution of the Medium and its Association with the Word 'Radio'. Radio Journal: International Studies In Broadcast \& Audio Media 14 (1), 00722.

Biewen J. and Dilworth A. eds (2017) Reality Radio: Telling True Stories in Sound, $2^{\text {nd }}$ edition. Chapel Hill, University of North Carolina Press.

Bloom, E. (2016) The Wireless Past: Anglo-Irish Writers and the BBC 1931-1968. New York: Oxford University Press.

Bottomley, A. (2015) Podcasting, Welcome to Night Vale, and the Revival of Radio Drama. Journal of Radio \& Audio Media. 22 (2), 179-189.

Brunel, R. (1936) Radio Magic Expected to Emerge from Columbia Workshop Experimentation. Washington Post, Sept 6. 
Cazeaux, C. (2005) Phenomenology and Radio Drama. The British Journal of Aesthetics. 45:3, 157-74

Chandler, D and Munday, R (2011) A Dictionary of Media and Communication. Oxford, Oxford University Press.

Cohen, D. R., Coyle, M., \& Lewty, J., eds (2009). Broadcasting Modernism. Gainesville, FL, University Press of Florida.

Crisell, A. (2006). Understanding Radio. New York, Routledge.

Crook, T (1999) Radio Drama: Theory and Practice. New York, Routledge.

Doctor, K. (2016) The Newsonomics of Podcasting. Neiman Lab. Available at http://www.niemanlab.org/collection/newsonomics-podcasting/ [Accessed 10 Feb, 2017].

Donaldson, S. (1992) Archibald MacLeish: An American Life. New York: Houghton Mifflin.

Drakakis, J., ed (1981) British Radio Drama. New York, Cambridge University Press.

Eco, U. (1990) The Limits of Interpretation. Bloomington, Indiana University Press.

Gilfillan, D. (2009). Pieces of Sound: German Experimental Radio. U of Minnesota Press.

Guralnick, E. (1995) Sight Unseen: Beckett, Pinter, Stoppard and Other Contemporary Dramatists on Radio. Columbus, Ohio University Press.

Hand R. and Traynor, M. (2008) The Radio Drama Handbook. New York, Continuum.

Hess, A. (2016) The Story So Far: Fiction Podcasts Take Their Next Steps. New York Times, Nov. 11 2016. Available at: https://www.nytimes.com/2016/11/13/arts/fiction-podcastshomecoming. [Accessed Jan 10, 2017]

Hilmes, M., \& Loviglio, J. eds (2002). Radio Reader: Essays in the Cultural History of Radio. New York, Routledge.

Hilmes, M. (2014) The Lost Critical History of Radio. Australian Journalism Review. 36 (2), 11-22.

Heyer, P. (2005) The Medium and the Magician: Orson Welles, The Radio Years, 1934-1952.

Toronto, Rowman and Littlefield.

Johnson, P. (2015) Editor's Remarks: Rethinking Radio. Journal of Radio \& Audio Media. 23 (1), 1-3. 
Kaplan, M. (1949). Radio and Poetry. New York, Columbia University Press.

Kahn, D., \& Whitehead, G. (1992). Wireless Imagination Sound, Radio, and the Avant-Garde. Cambridge, MA, MIT Press.

Kern, J. (2008) Sound Reporting: The NPR Guide to Audio Journalism and Production. Chicago, University of Chicago Press.

Kogawa, T. (2008) A Radioart Manifesto. Available at:

http://anarchy.translocal.jp/radioart/20080710AcousticSpacelssue_7.html [Accessed Feb 10, 2017].

Lacey, K. (2008) Ten Years of Radio Studies: The Very Idea. The Radio Journal: International Studies in Broadcast \& Audio Media 6 (1), 21-32.

Landry, R. (1946). The Improbability of Radio Criticism. Hollywood Review 2 (1), 66-70.

Lenthall, B. (2007) Radio's America: the Great Depression and the Rise of Modern Mass Culture. Chicago, University of Chicago Press.

Loviglio, J. and Hilmes, M., eds (2013). Radio's New Wave: Global Sound in a Digital Era. New York, Routledge.

Marvin, C. (1988) When Old Technologies Were New: Thinking about Electric Communication in the Late Nineteenth Century. New York, Oxford University Press.

McGill, E. (1940) Radio Directing. New York, McGraw-Hill.

McWhinnie, D. (1959) The Art of Radio. London, Faber and Faber.

Montague, S. (2017) Towards a Poetics of Audio: The Importance of Criticism. Available at: http://thesarahawards.com/article/2017/4/3/towards-a-poetics-of-audio-the-importance-ofcriticism [Accessed April 13, 2017]

Morris, J and Patterson, E. (2015) Podcasting and its Apps: Software, Sound and the Interfaces of Digital Audio. Journal of Radio and Audio Media 22 (2), 220-30.

Naremore, J. (1998) More Than Night: Film Noir in its Contexts. Berkeley, University of California Press.

Patterson, E. (2016) Reconfiguring Radio Drama after Television: The Historical Significance of Theater 5, Earplay and CBS Radio Mystery Theater as Post-network Radio Drama. Historical Journal of Film, Radio and Television. 36 (4), 649-67. 
Raeburn, P. (1998) Just Like the Old Days, Except for the .com. New York Times (Oct 25, 1998). Available at: http://www.nytimes.com/1998/10/25/arts/television-radio-just-like-the-old-daysexcept-for-the-com.html. [Accessed Feb 10, 2017].

Razlogova, E. (2011). The Listener's Voice: Early Radio and the American Public. Philadelphia, University of Pennsylvania Press.

Richman, J. and Allison, J. (2017) Radio Diaries: DIY Handbook. Radio Diaries.

Robinson, J. (2016) Oscar Isaac and Katherine Keener Present Your New Podcast Obsession. Vanity Fair (Nov). Available at: http://www.vanityfair.com/hollywood/2016/11/homecomingpodcast-oscar-isaac-catherine-keener-david-schwimmer-gimlet. [Accessed Jan 30, 2017].

Russo, A. (2010). Points on the Dial: Golden Age Radio Beyond the Networks. Durham, Duke University Press.

Smith, J. and Verma, N., eds (2016) Anatomy of Sound: Norman Corwin and Media Authorship. Oakland, CA: University of California Press.

Verma, N. (2012) Theater of the Mind: Imagination, Aesthetics and American Radio Drama. Chicago, University of Chicago Press.

Weiss, A. (2002) Breathless: Sound Recording, Disembodiment, and the Transformation of Lyrical Nostalgia. Middletown, Wesleyan University Press.

\section{Audio Dramas Studied}

Alice Isn't Dead (10 episodes, 2016)

Alien: Out of the Shadows (Audiobook, 2016)

Archive 81 (13 episodes, 2016-17)

Ars Paradoxica (20 episodes, 2015-17)

The Behemoth (20 episodes, 2016)

The Black Tapes (24 episodes, 2015-16)

The Bridge (3 episodes, 2016)

The Bright Sessions (8 episodes, 2015)

Bronzeville (7 episodes, 2017)

Campfire Radio Theater (10 episodes, 2013-17)

The Child (Audiobook, 2014)

Crimetown (11 episodes, 2016-17) 
Dark Adventure Radio Theater (8 CDs 2007-13)

The Disappearance of Mars Patel (10 episodes, 2016)

EOS 10 (18 episodes 2014-15)

Fruit (20 episodes, 2016)

Good Omens ( 6 episodes, 2015)

The Heart (3 episodes, 2015-16)

Homecoming (6 episodes, 2016)

Hollywood and Crime (9 episodes, 2017)

Inside Psycho (2 episodes, 2016)

The Leviathan Chronicles (10 episodes, 2008)

Lif-e.af/ter (10 episodes, 2016)

Limetown (6 episodes, 2015)

Lincoln in the Bardo (Audiobook, 2017)

Locke \& Key (audiobook, 2015)

The Message (8 episodes, 2015

The Mysterious Secrets of Uncle Bertie's Botanarium (21 episodes, 2016-17)

Neverwhere (6 episodes, 2013)

A Night Called Tomorrow (5 episodes, 2016)

Our Fair City (6 episodes, 2012)

The Orphans (4 episodes, 2016)

Serendipity (16 episodes, 2015-17)

Secrets, Crimes and Audiotape (3 episodes, 2016)

The Starling Project (Audiobook, 2014)

Stranglers (12 episodes, 2016-17)

Transmissions from Colony One (30 episodes, 2013-15)

The Truth ( 2 episodes 2013-15)

Unsolved Murders (3 episodes, 2016)

Welcome to Nightvale (55 episodes, 2012-17)

We're Alive (10 episodes, 2009)

Within the Wires (10 episodes, 2016)

Wolf 359 (6 episodes, 2014)

Wooden Overcoats (8 episodes, 2015) 


\section{NEIL VERMA}

Neil Verma is assistant professor of sound studies in Radio/Television/Film and associate director of the MA in Sound Arts and Industries at Northwestern University. Verma is author of Theater of the Mind: Imagination, Aesthetics, and American Radio Drama (Chicago, 2012), which won the 2013 Best First Book Award from the Society for Cinema and Media Studies. He is co-editor (with Jacob Smith) of Anatomy of Sound: Norman Corwin and Media Authorship (California, 2016). Verma has published articles on topics ranging from film history and television sound design to experimental listening and podcasting in The Cine-Files, Critical Quarterly, Journal of American Studies, Journal of Sonic Studies, RadioDoc Review, Recherches sémiotiques / Semiotic Inquiry, Sounding Out!, and The Velvet Light Trap. He is Network Co-director for the Radio Preservation Task Force at the Library of Congress, and founded the Great Lakes Association for Sound Studies (GLASS). He holds a PhD in History of Culture from the University of Chicago, where he was also Harper-Schmidt Fellow in the Society of Fellows from 2010-14.

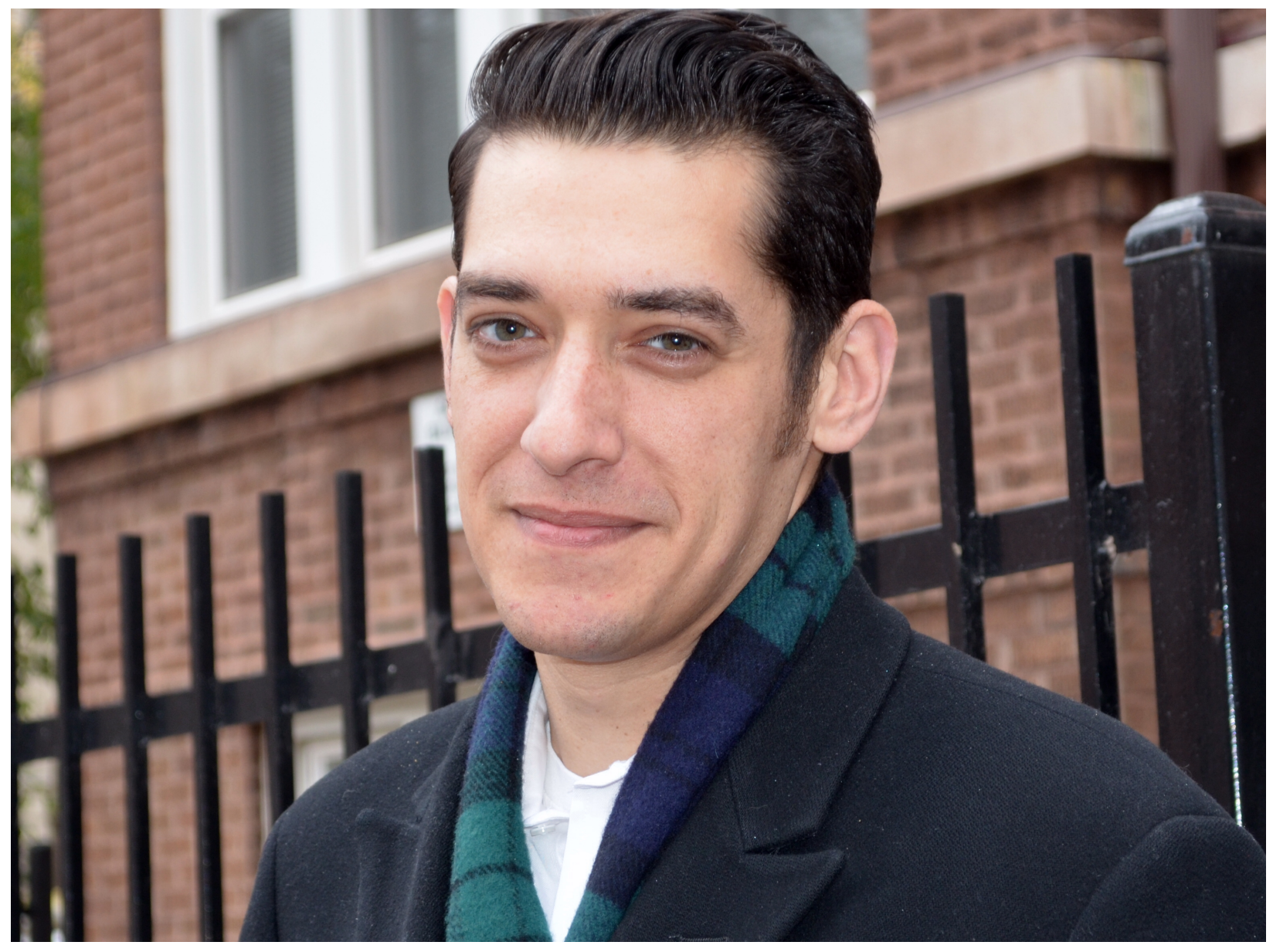

